\title{
QUANTITATIVE CHANGES IN MYOMETRIAL ACTIVITY IN THE GUINEA-PIG DURING PREGNANCY
}

\author{
D. G. PORTER* \\ Department of Physiology, Royal Veterinary College, London, $\mathcal{N} . W .1$
}

(Received 20th November 1970)

\begin{abstract}
Summary. Intrauterine pressure recordings were made in non-pregnant guinea-pigs, and in either the gravid horn of bilaterally pregnant, or the sterile horn of unilaterally pregnant animals. The results showed that, rather than a reduction of uterine activity during the luteal phase of the oestrous cycle, there was a significant increase compared with the level at oestrus. Activity during pregnancy was reduced compared with nonpregnant levels and this reduction was accomplished by a lowered frequency of pressure cycles while their amplitude remained unchanged. The activity of the gravid horn was significantly less than that of the sterile horn during the mid-third of pregnancy. Both the sterile and gravid horns responded to oxytocin at all stages of pregnancy. From these results, it is suggested that progesterone may not be a myometrial regulatory agent in the guinea-pig.
\end{abstract}

\section{INTRODUGTION}

It is uncertain whether progesterone plays a rôle in the regulation of normal myometrial function in the guinea-pig. Zarrow, Anderson \& Callantine (1963) and Schofield (1964) reported that parturition in the guinea-pig could not be delayed by the systemic administration of progesterone. Not only was this confirmed recently (Porter, 1969, 1970), but it was also found that even the intrauterine administration of large doses of progesterone failed to prevent delivery occurring at the normal time. Furthermore, in the non-pregnant animal, neither systemic nor intrauterine progesterone treatment had an effect upon the mechanical activity of the uterus in vivo; a finding in contrast to the well documented effects of progesterone on myometrial activity in the rabbit (Csapo \& Takeda, 1965; Porter, 1968).

These findings raise the question of how the uterine mechanical activity is regulated normally during the oestrous cycle and pregnancy in the normal guinea-pig. Accordingly, a study was made of intrauterine pressure in guineapigs at different stages of the oestrous cycle and during pregnancy. Recordings from pregnant animals were made either from the sterile horn of unilaterally pregnant animals or from the gravid horn of bilaterally pregnant animals. The object of these experiments was to provide information on the following

* Present address: Department of Anatomy, Harvard Medical School, Boston, Mass., U.S.A. 
problems: (i) is the guinea-pig uterus quiescent during the luteal phase and during pregnancy, (ii) if not, how does the activity compare with that of the oestrous animal, and (iii) is there a local influence of the conceptus on myometrial activity during pregnancy?

\section{MATERIALS AND METHODS}

\section{Pregnant animals}

Thirty pregnant guinea-pigs of mixed strain from a closed colony were used. The animals were bred at random and were not selected for the experiments on the basis of age or parity. However, most of the females used were young (i.e. less than 1 year) and were primiparous. Accurately dated pregnancies were obtained by placing oestrous females individually with bucks overnight and finding copulatory plugs the following morning. Unilaterally pregnant animals were produced by mating females which had previously undergone unilateral salpingectomy.

The recording technique was similar to that described earlier (Porter, 1970). Recording balloons of $1.5-\mathrm{ml}$ capacity were inserted into the gravid horns, whereas the balloons which were inserted into the sterile horns varied from $1.5-\mathrm{ml}$ to $50-\mathrm{ml}$ capacity depending on the stage of pregnancy.

Following recovery of the animals from surgery, intrauterine pressure was monitored continuously for periods of up to 1 week. In each case, after spontaneous activity had been recorded for a period in excess of $1 \mathrm{hr}$, the animals were given an intramuscular injection of $25 \mathrm{mU}$ oxytocin in $0.1 \mathrm{ml}$ saline to determine the responsiveness of the uterus to a standard dose of the hormone.

\section{Non-pregnant animals}

Intrauterine pressure was monitored in nine non-pregnant guinea-pigs either during oestrus (three) as detected by vaginal opening, or during the dioestrum (six) in order to determine whether mechanical activity varied during the oestrous cycle.

The intrauterine pressure recordings were analysed for frequency of pressure cycles (a pressure cycle was arbitrarily designated as any cycle of 5 or more $\mathrm{mm} \mathrm{Hg}$ amplitude) and for mean, and maximum amplitude. These analyses were made separately for each hour of 2-hr records taken at random from nonpregnant animals, and 2-hr records (where possible) preceding each oxytocin test from pregnant animals. In the case of pregnant animals, only records obtained from animals known to be carrying live foetuses at the time the recordings were made were included in the data. The presence of live foetuses was determined either by palpation of foetal movement if pregnancy was sufficiently advanced, or by the observation of foetal heart movements post mortem immediately after the recording period.

All amplitude measurements were corrected for differences in the radii of the uterine horns. This correction is essential as was emphasized by Anderson, Turnbull \& Murray (1967) since the intrauterine pressure produced by a given tension in the myometrium is inversely proportional to the radius of the uterine horn. By correcting the amplitude data on the basis of an arbitrarily selected 
uterine radius $(0.5 \mathrm{~cm})$, it was possible to render the intrauterine pressures directly proportional to myometrial tension so that the functional state of the uterine muscle could be compared among animals in various stages of the cycle and pregnancy and equipped with balloons of different volumes in either sterile or gravid horns. The radii of the uteri of animals carrying balloons in sterile horns (non-pregnant and unilaterally pregnant) could be estimated from a knowledge of the length and volume of the balloon. The radii of gravid horns was estimated from the weight of the conceptus adjacent to the recording balloon and measurements of the foetal length/width relationship. By means of the Law of Laplace (see Freiberger, 1960), the amplitude data were corrected as follows:

$$
\begin{array}{ll}
\text { (i) } \mathrm{P}_{\mathrm{a}}=\frac{2 \mathrm{~T}_{\mathrm{a}}}{\mathrm{r}_{\mathrm{a}}} & \text { (ii) } \mathrm{P}_{\mathrm{c}}=\frac{2 \mathrm{~T}_{\mathrm{c}}}{\mathrm{r}_{\mathrm{c}}}
\end{array}
$$

where $\mathrm{P}=$ mean amplitude of pressure cycles

$\mathrm{T}=$ tension of myometrium (actually the product of wall thickness and tension)

$\mathrm{r}=$ radius of curvature of uterine horn

$\mathrm{a}=$ actual

$c=$ corrected

Let

$$
\mathrm{T}_{\mathrm{a}}=\mathrm{T}_{\mathrm{c}}
$$

then

But

$$
\text { (iii) } P_{c}=P_{a} \cdot \frac{r_{a}}{r_{c}}
$$

$$
r_{c}=0.5 \text { (arbitrary) }
$$

then

$$
\text { (iv) } P_{c}=P_{a} \cdot \frac{r_{a}}{0.5}
$$

In order to obtain a numerical assessment of total activity, the product of frequency and mean (corrected) amplitude was calculated to give a single 'activity unit'. This unit is equivalent to Montevideo Units (Caldeyro-Barcia \& Poseiro, 1959) except that frequency was expressed as pressure cycles per hr instead of per $10 \mathrm{~min}$.

\section{RESULTS}

\section{Non-pregnant animals}

The mechanical activity of the uterus in non-pregnant guinea-pigs was characterized as reported earlier (Porter, 1970) by regular bursts of pressure cycles of a mean (corrected) amplitude of about $10 \mathrm{~mm} \mathrm{Hg}$ and a maximum of $20 \mathrm{~mm} \mathrm{Hg}$. These bursts were separated by quiescent periods varying in duration from 4 to $30 \mathrm{~min}$. Analysis of the records is summarized in Table 1.

It was found that whereas both the mean amplitude and the mean maximum 
amplitude of pressure cycles were significantly greater in dioestrous than in oestrous animals, the difference in the frequency was not statistically significant.

\section{Pregnant animals}

It was found that recording balloons could not be placed in the gravid horn of guinea-pigs before the 30th day of pregnancy without causing death of the conceptuses. In the sterile horn, balloons could be placed at any time without interrupting pregnancy.

Analysis of the recordings from the gravid horns showed that there was significantly less 'total activity' than was found in non-pregnant animals (Table 2). Nevertheless, some activity was present at all stages and tended to increase towards term (Plate 1). Breakdown of activity units into frequency and mean (corrected) amplitude revealed that the reduction in activity in pregnancy was brought about by a decrease in the frequency of pressure cycles while

TABLE 1

UTERINE MEGHANICAL AGTIVITY IN NON-PREGNANT GUINEA-PIGS

\begin{tabular}{|c|c|c|c|c|c|}
\hline Stage & $\begin{array}{c}\text { No. of } \\
\text { animals }\end{array}$ & $\begin{array}{c}\text { Mean } \\
\text { corrected } \\
\text { amplitude } \\
(\mathrm{mm} \mathrm{Hg})\end{array}$ & $\begin{array}{l}\text { Frequency } \\
\text { (gycles/hr) }\end{array}$ & $\begin{array}{c}\text { Activity } \\
\text { units }\end{array}$ & $\begin{array}{c}\text { Mean } \\
\text { corrected } \\
\text { maximum } \\
\text { amplitude } \\
(\text { mm Hg })\end{array}$ \\
\hline $\begin{array}{l}\text { Oestrus } \\
\text { Dioestrus }\end{array}$ & $\begin{array}{l}3 \\
6\end{array}$ & $\begin{array}{r}7 \cdot 8 \pm 2 \cdot 3 \\
12 \cdot 8 \pm 2 \cdot 7 \\
P<0 \cdot 025\end{array}$ & $\begin{array}{c}18 \cdot 8 \pm 3 \cdot 9 \\
25 \cdot 0 \pm 4 \cdot 0 \\
\text { N.S. }\end{array}$ & $\begin{array}{c}129 \pm 31 \cdot 8 \\
357 \pm 60 \cdot 0 \\
P<0 \cdot 025\end{array}$ & $\begin{array}{c}13 \cdot 3 \pm 1 \cdot 27 \\
20 \cdot 2 \pm 0 \cdot 81 \\
P<0.001\end{array}$ \\
\hline
\end{tabular}

the mean amplitude and the mean maximum amplitude remained unchanged (Table 2).

In the sterile horn up to Day 28 of pregnancy, the level of 'total activity' varied considerably from as high as that in non-pregnant animals to levels comparable to those of the gravid horn. As in the gravid horn, however, the variations in activity were attributable to variations in frequency of the pressure cycles alone since no significant change occurred in the mean amplitude or mean maximum amplitude (Table 2, Plate 2).

During the mid-gestational period (28 to 46 days), the level of activity in the sterile horn was at a minimum which was significantly less than non-pregnant levels $(P<0.01)$ but significantly greater than the levels recorded from gravid horns $(P<0.005)$. From Day 46 to immediately before parturition, there was no significant difference between the levels of activity in the sterile and gravid horns (Table 2).

\section{Oxytocin tests}

It was found that both the sterile and gravid horns responded at all stages of pregnancy tested to a single intramuscular injection of $25 \mathrm{mU}$ oxytocin with a significant increase in frequency of pressure cycles (Table 3 ). However, although 


\section{PLATE 1}

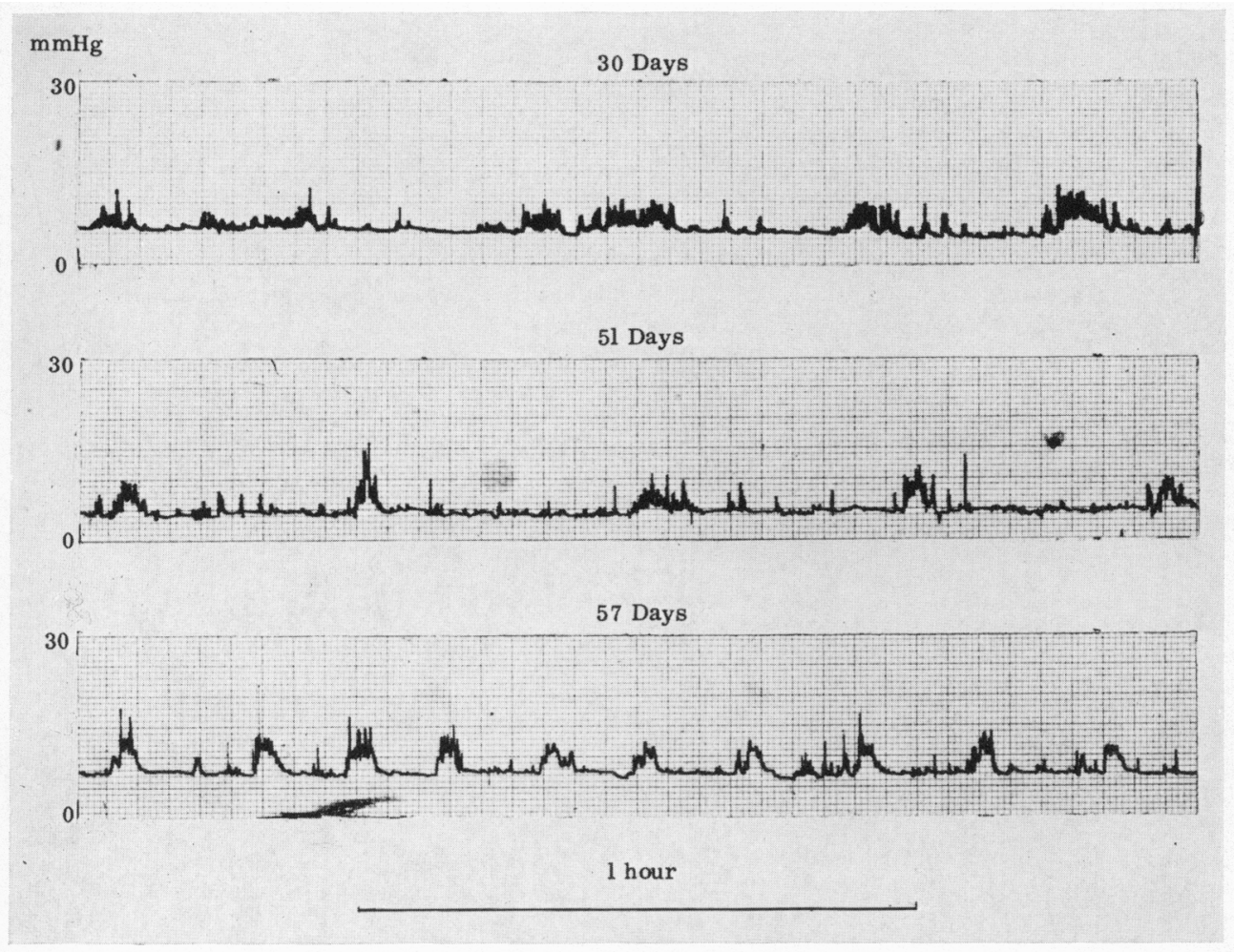

Intrauterine pressure recordings from the gravid horn of three guinea-pigs $(30,51$ and 57 days). Note the presence of pressure cycles in all three recordings. 
PLATE 2

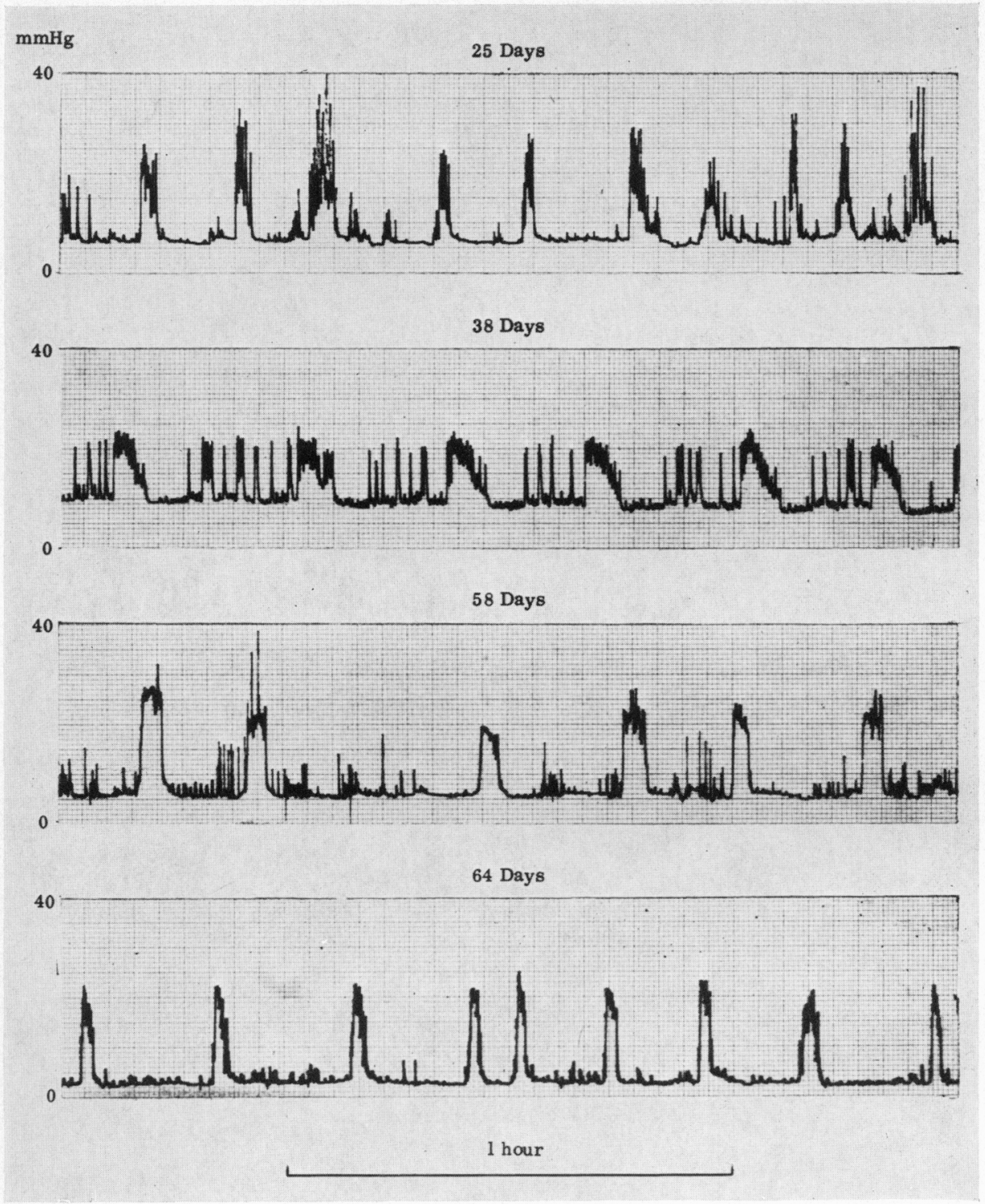

Intrauterine pressure recordings from the sterile horns of four pregnant guinea-pigs 225 . 38,58 and 64 days). Note the presence of high amplitude contractions in all records. 
TABle 2

ANALYSIS OF INTRAUTERINE PRESSURE RECORDINGS FROM PREGNANT GUINEA-PIGS

\begin{tabular}{|c|c|c|c|c|c|c|c|}
\hline & $\begin{array}{c}\text { Day of } \\
\text { pregnancy }\end{array}$ & $\begin{array}{c}\text { Animal } \\
\text { no. }\end{array}$ & $\begin{array}{c}\text { Mean } \\
\text { amplitude } \\
(m m H g)\end{array}$ & $\begin{array}{c}\text { Mean } \\
\text { amplitude } \\
\text { corrected } \\
(\mathrm{mm} \mathrm{Hg})\end{array}$ & $\begin{array}{l}\text { Frequency } \\
\text { (cycles/hr) }\end{array}$ & $\begin{array}{c}\text { Activity } \\
\text { units } \\
F \times \text { mean } \\
\text { amplitude } \\
\text { corrected }\end{array}$ & $\begin{array}{c}\text { Maximum } \\
\text { amplitude } \\
\text { (mm Hg) } \\
\text { corrected }\end{array}$ \\
\hline $\begin{array}{l}\text { Balloon in } \\
\text { sterile horn }\end{array}$ & $\begin{array}{l}15 \\
16 \\
16 \\
18 \\
25 \\
29 \\
33 \\
34 \\
38 \\
41 \\
42 \\
51 \\
53 \\
54 \\
54 \\
58 \\
60 \\
65 \\
65 \\
66 \\
66\end{array}$ & $\begin{array}{l}13^{*} \\
37 \\
50 \\
10 \\
14 \\
29 \\
15^{*} \\
31^{*} \\
18^{*} \\
22 \\
41 \\
28 \\
20^{*} \\
16^{*} \\
39 \\
25 \\
49 \\
43 \\
23 \\
48 \\
47\end{array}$ & $\begin{array}{r}13.0 \\
10.0 \\
11.5 \\
19.0 \\
24.0 \\
9.0 \\
10.0 \\
8.0 \\
12.0 \\
14.0 \\
6.5 \\
5.0 \\
10.0 \\
8.0 \\
14.0 \\
11.0 \\
10.0 \\
11.5 \\
13.5 \\
11.5 \\
9.0\end{array}$ & $\begin{array}{r}6 \cdot 5 \\
9 \cdot 2 \\
5 \cdot 8 \\
17 \cdot 5 \\
16 \cdot 3 \\
5 \cdot 8 \\
9 \cdot 6 \\
4 \cdot 6 \\
7 \cdot 7 \\
12 \cdot 0 \\
14 \cdot 6 \\
6 \cdot 5 \\
5 \cdot 6 \\
3 \cdot 5 \\
29 \cdot 5 \\
6 \cdot 7 \\
16 \cdot 5 \\
21 \cdot 1 \\
6 \cdot 8 \\
7 \cdot 4 \\
6 \cdot 2\end{array}$ & $\begin{array}{r}21 \cdot 0 \\
8.0 \\
7 \cdot 5 \\
15 \cdot 0 \\
4 \cdot 0 \\
5 \cdot 5 \\
6 \cdot 0 \\
6 \cdot 0 \\
11 \cdot 0 \\
3 \cdot 0 \\
4.0 \\
4.0 \\
3 \cdot 0 \\
3 \cdot 0 \\
4.5 \\
4.5 \\
4.5 \\
5.0 \\
1.5 \\
2.5 \\
5.0\end{array}$ & $\begin{array}{r}137 \\
74 \\
43 \\
263 \\
65 \\
32 \\
58 \\
28 \\
85 \\
36 \\
58 \\
26 \\
17 \\
11 \\
133 \\
27 \\
74 \\
106 \\
10 \\
19 \\
31\end{array}$ & $\begin{array}{r}15 \\
16 \\
9 \\
27 \\
20 \\
9 \\
13 \\
7 \\
10 \\
12 \\
25 \\
9 \\
10 \\
5 \\
28 \\
10 \\
26 \\
24 \\
8 \\
10 \\
9\end{array}$ \\
\hline $\begin{array}{l}\text { Balloon in } \\
\text { gravid horn }\end{array}$ & $\begin{array}{l}30 \\
36 \\
37 \\
40 \\
51 \\
56 \\
58 \\
61 \\
64\end{array}$ & $\begin{array}{r}35 \\
8 \\
9 \\
12 \\
21 \\
32 \\
27 \\
45 \\
34\end{array}$ & $\begin{array}{l}5 \cdot 0 \\
7 \cdot 0 \\
6 \cdot 0 \\
5 \cdot 0 \\
8 \cdot 5 \\
3 \cdot 0 \\
3 \cdot 0 \\
8 \cdot 0 \\
5 \cdot 5\end{array}$ & $\begin{array}{r}6.5 \\
14.9 \\
13 \cdot 8 \\
11.5 \\
27 \cdot 3 \\
9.7 \\
9.7 \\
25 \cdot 8 \\
18.7\end{array}$ & $\begin{array}{l}2 \cdot 0 \\
1.5 \\
1.5 \\
2 \cdot 7 \\
2 \cdot 5 \\
0.5 \\
1.5 \\
5.5 \\
2 \cdot 5\end{array}$ & $\begin{array}{r}13 \\
22 \\
21 \\
31 \\
68 \\
5 \\
15 \\
142 \\
47\end{array}$ & $\begin{array}{r}4 \\
8 \\
13 \\
6 \\
20 \\
10 \\
11 \\
28 \\
9\end{array}$ \\
\hline
\end{tabular}

Each figure represents the mean of two values/animal except where designated * where only one value was obtained.

TABLE 3

OXYTOGIN TESTS

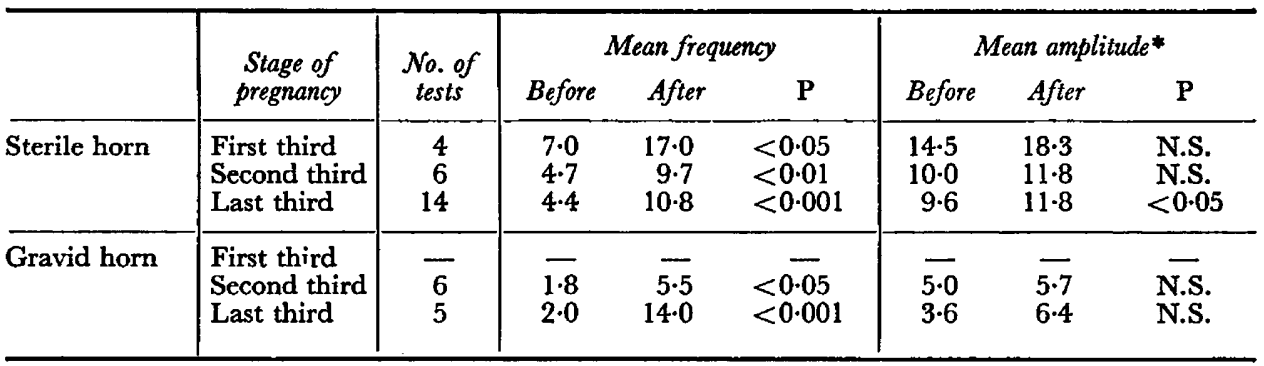

$P=$ probability; N.S. = not significant.

* Uncorrected, since paired data were from the same animal (i.e. no volume change). 
there was also a slight increase in the mean amplitude of pressure cycles recorded after each oxytocin treatment, these changes were statistically significant only in the sterile horn during the last third of pregnancy.

\section{DISGUSSION}

The finding that the frequency of intrauterine pressure cycles increases, albeit not significantly, during the luteal phase of the oestrous cycle in the guinea-pig is consistent with the observations in vitro of Greig (1939), and of Keye (1923) on the uterus of the sow. However, the significant increase in the amplitude of the pressure cycles is contrary to the well-documented findings of a depressant effect of the corpus luteum on myometrial activity in the rabbit (Knaus, 1926; Allen \& Corner, 1929; Schofield, 1957), human female (Knaus, 1934; Csapo \& Pinto-Dantas, 1966; Coutinho, 1968) and cow (Evans \& Miller, 1936; Porter, unpublished work) in vivo, and sow (Keye, 1923) and cow (Cupps \& Asdell, 1944) in vitro. Although this apparent species difference cannot be explained as yet, it is consistent with earlier findings (Porter, 1969, 1970) that exogenous progesterone had no inhibitory action upon myometrial activity in the non-pregnant guinea-pig.

The results of the experiments on pregnant guinea-pigs revealed a similarity to the human female (Csapo \& Sauvage, 1968), and possibly the rat (Fuchs, 1969), in that pressure cycles could be recorded from the uterus during most of pregnancy. This contrasts sharply with the rabbit, in which species no significant pressure cycles can be recorded during pregnancy until immediately before parturition (Fuchs, 1964; Porter \& Schofield, 1966). The frequency of pressure cycles recorded from both sterile and gravid horns throughout pregnancy was markedly reduced compared with those of the non-pregnant uterus. This is consistent with earlier findings in vitro of Newton (1933), although the complete extinction of activity reported in late pregnancy by this author was not observed in the present study. The corrected amplitude (i.e. equivalent to the intensity of myometrial contractions) of pressure cycles, however, was unaltered through pregnancy, a finding which, as further discussed below, supports the view that progesterone is not the principal myometrial regulating agent in the guinea-pig. The finding that the guinea-pig uterus was responsive to oxytocin throughout pregnancy was again consistent with the findings of Newton (1933) but differed from that for the rabbit uterus which is refractory to oxytocin until shortly before term (Knaus, 1926; Schofield, 1957).

The major effects of progesterone upon the myometrium have been described extensively in the rabbit and in this species it has been shown to reduce significantly the amplitude of uterine pressure cycles (Csapo \& Takeda, 1965; Porter, 1968) without a consistent effect upon their frequency and also to reduce the response to oxytocin (Csapo \& Lloyd-Jacob, 1961; Csapo \& Takeda, 1965). The inactivity of the myometrium and its refractoriness to oxytocin during pregnancy have been shown to be due to progesterone secreted by the corpus luteum (Knaus, 1926; Allen \& Corner, 1929; Allen \& Heckel, 1939; Wu \& Allen, 1959). Thus, the present results suggest that myometrial activity during pregnancy in the guinea-pig is either not regulated by the action of progesterone, 
or that the mechanism of action of progesterone in the guinea-pig differs from that in the rabbit. The former alternative is supported by the findings mentioned above (Porter, 1969, 1970) that exogenous progesterone is without effect on the duration of pregnancy or on the mechanical activity of the uterus of the nonpregnant guinea-pig.

Whatever the mechanism involved in regulating myometrial activity in the guinea-pig, its action is not restricted to the gravid horn since the sterile horn in pregnant animals also exhibited a loss of frequency of pressure cycles. The fact that the loss of activity in the gravid horn was significantly greater than in the sterile horn during the middle third of pregnancy, suggests that the mechanism originates in the conceptuses and although it exerts its major action upon the gravid horn, it has systemic effects. This view is consistent with the fact that the ovaries (Herrick, 1928; Heap \& Deanesly, 1966) and pituitary (Pencharz \& Lyons, 1934; Nelson, 1935) can be removed in the latter half of pregnancy without causing abortion.

\section{ACKNOWLEDGMENTS}

I am indebted to Mrs Cynthia Doughty for technical and surgical assistance and to the Agricultural Research Council for financial assistance with this work Grant No. AG 48/19.

\section{REFERENCES}

Allen, W. M. \& Corner, G. W. (1929) Physiology of corpus luteum: in normal growth and implantation of embryos after early ablation of the ovaries under the influence of extracts of the corpus luteum. Am. 7. Physiol. 88, 340.

Allen, W. M. \& Heckel, G. P. (1939) Maintenance of pregnancy by progesterone in rabbits castrated on the 11 th day. Am. F. Physiol. 125, 31.

Anderson, A. B., Turnbule, A. \& Murray, A. (1967) The relationship between amniotic fluid pressure and uterine wall tension in pregnancy. Am. J. Obstet. Gynec. 97, 992.

Caldeyro-Barcia, R. \& Poseiro, J. J. (1959) Oxytocin and contractility of the pregnant human uterus. Ann. N.Y. Acad. Sci. 75, 813.

Coutinho, E. M. (1968) Hormonal effects on the non-pregnant human uterus. Progress in Endocrinology, Proceedings 3rd International Congress of Endocrinology, Mexico, pp. 945-951.

Csapo, A. I. \& LlOYD-JAGOB, M. A. (1961) Effect of progesterone on pregnancy. Nature, Lond. 192, 329.

Csapo, A. I. \& Pinto-Dantas, C. R. (1966) The cyclic activity of the non-pregnant human uterus. Fert. Steril. 17, 34.

Csapo, A. I. \& Sauvage, J. (1968) The evolution of uterine activity during human pregnancy. Acta obstet. gynec. scand. $\mathbf{4 7}, 181$.

Csapo, A. I. \& TAKEDA, H. (1965) Effect of progesterone on the electric activity and intra-uterine pressure of pregnant and parturient rabbits. Am. F. Obstet. Gynec. 91, 221.

Cupps, P. T. \& Asdele, S. A. (1944) Changes in the physiology and pharmacology of the uterine muscle of the cow in relation to the estrous cycle. F. Anim. Sci. 3, 351.

Evans, E. I. \& Miller, F. W. (1936) Uterine motility in the cow. Am. F. Physiol. 116, 44.

FREIBERGER, W. F. (Ed.) (1960) International dictionary of applied mathematics. D. van Nostrand-Reinhold, Co., New York.

Fuchs, A. R. (1964) Oxytocin and the onset of labour in rabbits. F. Endocr. 30, 217.

Fuchs, A. R. (1969) Uterine activity in late pregnancy and during parturition in the rat. Biol. Reprod. $1,344$.

Greig, K. A. (1939) The uterine motility cycle in the guinea pig. Am. F. Physiol. 125, 547.

Heap, R. B. \& Deanesly, R. (1966) Progesterone in systemic blood and placentae of intact and ovariectomized pregnant guinea pigs. F. Endocr. 34, 417. 
HERRICK, E. H. (1928) The duration of pregnancy in guinea-pigs after removal and also after transplantation of the ovaries. Anat. Rec. 39, 193.

KEYE, J. D. (1923) Periodic variations in spontaneous contractions of uterine muscle, in relation to the oestrous cycle and early pregnancy. Bull. Fohns Hopkins Hosp. 34, 60.

KNaus, H. H. (1926) Action of pituitary extract upon the pregnant uterus of the rabbit. F. Physiol., Lond. 61, 383.

Knaus, H. H. (1934) Periodic fertility and sterility in women. Mandrick, Vienna. (Translated by Kitchin and Kitchin.)

Nelson, W. O. (1935) The effect of hypophysectomy upon mammary gland development and function in the guinea pig. Proc. Soc. exp. Biol. Med. 33, 222.

Newton, W. H. (1933) The normal behaviour of the isolated uterus of the guinea pig and its reactions to oestrin and oxytocin. F. Physiol., Lond. 79, 301.

Pencharz, R. I. \& Lyons, W. R. (1934) Hypophysectomy in the pregnant guinea pig. Proc. Soc. exp. Biol. Med 31, 1131 .

Porter, D. G. (1968) The local effect of intra-uterine progesterone treatment on myometrial activity in rabbits. F. Reprod. Fert. 15, 437.

Porter, D. G. (1969) Progesterone and the guinea-pig myometrium. In: Ciba Foundation Study Group No. 34, Progesterone: its regulatory effect on the myometrium, pp. 79-88. Eds. G. E. W. Woistenholme and J. Knight. Ghurchill, London.

Porter, D. G. (1970) The failure of progesterone to affect myometrial activity in the guinea-pig. F. Endocr. 46, 425.

Porter, D. G. \& Schofield, B. M. (1966) Intra-uterine pressure changes during pregnancy and parturition in rabbits. F. Endocr. 36, 291.

Schofield, B. M. (1957) The hormonal control of myometrial function during pregnancy. F. Physiol., Lond. 138, 1.

Schofield, B. M. (1964) Myometrial activity in the pregnant guinea-pig. F. Endocr. 30, 347.

Wv, D. H. \& ALLEN, W. M. (1959) Maintenance of pregnancy in castrated rabbits by $17 \alpha$ hydroxyprogesterone caproate and by progesterone. Fert. Steril. 10, 439.

Zarrow, M. X., Anderson, N. G. \& Gallantine, M. R. (1963) Failure of progesterone to prolong pregnancy in the guinea pig. Nature, Lond. 198, 690. 